\title{
ORIGINAL ARTICLE Prospective research on infants with mild encephalopathy: the PRIME study
}

\author{
C Prempunpong ${ }^{1}$, LF Chalak ${ }^{2}$, J Garfinkle ${ }^{3}$, B Shah ${ }^{4}$, V Kalra ${ }^{5}$, N Rollins², R Boyle ${ }^{3}$, K-A Nguyen ${ }^{3}$, I Mir ${ }^{2}$, A Pappas ${ }^{5}$, P Montaldo ${ }^{6}$, \\ S Thayyil ${ }^{6}$, PJ Sánchez ${ }^{7}$, S Shankaran ${ }^{5}$, AR Laptook ${ }^{4}$ and G Sant'Anna ${ }^{3}$
}

OBJECTIVE: To determine short-term outcomes of infants with evidence of hypoxia-ischemia at birth and classified as mild neonatal encephalopathy (NE) at $<6 \mathrm{~h}$ of age.

STUDY DESIGN: Prospective multicenter study. Mild NE was defined as $\geqslant 1$ abnormal category in modified Sarnat score. Primary outcome was any abnormality on early amplitude integrated electroencephalogram (aEEG) or seizures, abnormal brain magnetic resonance imaging (MRI) or neurological exam at discharge.

RESULTS: A total of $54 / 63(86 \%)$ of enrolled infants had data on components of the primary outcome, which was abnormal in 28/54 (52\%): discontinuous aEEG $(n=4), \mathrm{MRI}(n=9)$ and discharge exam $(n=22)$. Abnormal tone and/or incomplete Moro were the most common findings. MRI abnormalities were confined to cerebral cortex but two infants had basal ganglia and/or thalamus involvement. The 18 to 24 months follow-up is ongoing.

CONCLUSIONS: A larger than expected proportion of mild NE infants with abnormal outcomes was observed. Future research should evaluate safety and efficacy of neuroprotection for mild NE.

Journal of Perinatology (2018) 38, 80-85; doi:10.1038/jp.2017.164; published online 2 November 2017

\section{INTRODUCTION}

Neonatal encephalopathy (NE) secondary to a perinatal hypoxicischemic event remains an important cause of neurodevelopmental impairment and death. ${ }^{1}$ First described by Sarnat and Sarnat in $1976^{2}$, NE was classified as mild, moderate or severe based on neurological signs. Infants in whom the worst level of encephalopathy during hospitalization was mild had few if any adverse outcomes. ${ }^{2-5}$ Recently, studies have suggested that some infants with perinatal acidosis and mild NE diagnosed at $<6 \mathrm{~h}$ of age have neurological abnormalities at discharge from the neonatal intensive care unit $(\mathrm{NICU}){ }_{1}^{6}$ cerebral findings of hypoxic-ischemic injury on brain magnetic resonance imaging $(\mathrm{MRI}){ }^{7}$ or high rates of disability at 5 years of age. ${ }^{8}$ However, a prospective and systematic evaluation of the frequency of neurological abnormalities of these mild NE infants is lacking.

Therapeutic hypothermia has been studied rigorously in six randomized trials in infants with moderate or severe hypoxicischemic NE. ${ }^{9-14}$ Hypothermia was associated with a reduction in death and childhood disability ${ }^{15,16}$ and has been adopted widely by the neonatal community. Infants with mild NE were not eligible in the trials since the frequency of abnormalities was expected to be low. ${ }^{4,5}$ However, registries of infants who received therapeutic hypothermia indicate a drift in clinical practice with hypothermia being offered to some infants with mild NE at $<6 \mathrm{~h}$ of age. ${ }^{17-19}$ Therefore, we undertook the 'Prospective Research on Infants with Mild Encephalopathy: The PRIME study' to determine the frequency of abnormalities detected in this population by assessing early amplitude integrated electroencephalogram (aEEG), brain MRI at $<30$ days of age or neurological examination at discharge from the NICU. Such knowledge is essential to define whether clinical trials of neuroprotective strategies that target newborns with mild NE are feasible and warranted.

\section{METHODS}

Study design and population

This prospective observational multicenter study was conducted at 6 academic perinatal centers from December 2012 to October 2015 (NCT01747863). Infants were screened if they were admitted to the NICU, $\geqslant 36$ weeks of gestation and had evidence of hypoxia-ischemia during the perinatal period. The later included a $\mathrm{pH} \leqslant 7.0$ or a base deficit $\geqslant 16 \mathrm{mmolI}^{-1}$ in arterial or venous umbilical cord blood or any blood specimen during the 1 st hour after birth. If the $\mathrm{pH}$ was 7.01 to 7.15 , or base deficit 10 to $15.9 \mathrm{mmol}$ per liter, or if a blood gas was not available, additional criteria were required. These included an acute obstetric event (for example, late or variable decelerations, cord prolapse, cord rupture, uterine rupture, maternal trauma, hemorrhage or cardiorespiratory arrest) and either a 10-min Apgar score $\leqslant 5$ or assisted ventilation initiated at birth and continued $\geqslant 10 \mathrm{~min}$. Infants who fulfilled these criteria underwent a standardized neurological examination at $<6 \mathrm{~h}$ of age using the Sarnat score as modified by the Eunice Kennedy Shriver National Institute of Child Health and Human Development NICHD-NRN (Neonatal Research Network) trial of hypothermia. ${ }^{10}$ The score evaluated six categories: level of consciousness, spontaneous activity, posture, tone, primitive reflexes (suck and Moro) and autonomic nervous system (pupils, heart rate and respiration). Each category was scored for pre-defined signs consistent with normal, mild, moderate or severe. Infants with $\geqslant 1$ abnormal category but no evidence of moderate or severe NE (defined as moderate and/or severe abnormality in three categories) were classified as mild NE. Exclusion criteria included a completely normal neurological exam, inability to enroll at $\leqslant 6 \mathrm{~h}$ of life, presence of a major congenital abnormality or severe growth restriction (birth weight $\leqslant 1800 \mathrm{~g}$ ). The

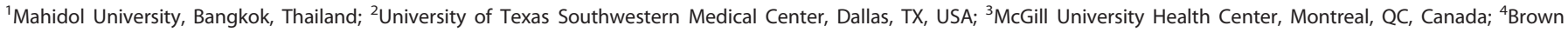

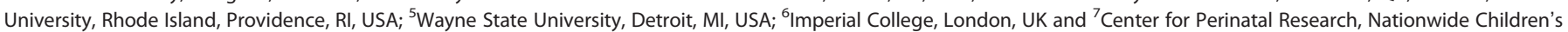

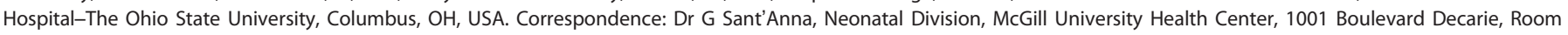
B05.2711 Montreal, H4A3J1, QC, Canada.

E-mail: guilherme.santanna@mcgill.ca

Received 14 February 2017; revised 18 July 2017; accepted 28 August 2017; published online 2 November 2017 
Institutional Review Board of each participating center approved the study and written informed consent was obtained from parents.

\section{Study procedures and data collection}

All infants enrolled were treated according to the standard of care of each center and none of them received hypothermia. Study related measurements assessed three short-term outcomes based on their association with neurodevelopmental impairment at 18-24 months of age: early aEEG $(<9 \mathrm{~h} \text { of age })^{20-22}$ or clinical seizures,,$^{23,24}$ brain $\mathrm{MR}^{25-27}$ and neurological exam at NICU discharge. ${ }^{28,29}$ The timing of the early aEEG was based on feasibility reasons in order that outborn infants could also be monitored. The Olympic BrainZ Monitor (Natus Medical Incorporated, USA) or the Olympic CFM 6000 (Natus Medical Incorporated) were used. Five leads were applied: C3, C4, P3, P4 and ground. Electrode locations were measured using the modified international 10/20 electrode placement system. Hydrogel or needle electrodes were applied to the site, and secured with a thin strip of hypoallergenic tape or a turban of gauze placed around the infant's head. Recordings were done for a minimum duration of $60 \mathrm{~min}$. At the end of the study, aEEG tracings were deidentified and analysis performed by two independent investigators (LC and AP) blinded to the clinical outcomes. The aEEG background was classified as follows: $:^{30,31}$ (a) continuous normal voltage (maximum voltage $=10$ to $50 \mu \mathrm{V}$, and minimum voltage $=5$ to $10 \mu \mathrm{V}$ ); (b) discontinuous normal voltage (DNV, periods of low voltage below $5 \mu \mathrm{V}$, whereas upper border voltage is $>10 \mu \mathrm{V}$ ); (c) burst suppression (periods of very low voltage $(<5 \mu \mathrm{V})$ without variability intermixed with bursts of higher amplitude $>25 \mu \mathrm{V}$ ); (d) continuous low voltage (continuous background and maximum voltage $<5 \mu \mathrm{V}$ ); or (e) flat tracing (inactive background and very low voltage $(<5 \mu \mathrm{V})$ ). The raw EEG was also reviewed for any evidence of seizures. The short nature of the recordings precluded a conclusive evaluation of sleep-wake cycles. An abnormal aEEG was defined by the presence of non-continuous background pattern (DNV, burst suppression, continuous low voltage or flat tracing) or seizures. Any disagreement between the investigators was resolved by adjudication.

Brain MRI was obtained at $<30$ days of age and without sedation using $\mathrm{T} 1$ and $\mathrm{T} 2$ weighted sequences and diffusion weighted images at either 1.5 or $3 \mathrm{~T}$. MRI studies were scored using the validated NICHD-NRN scoring system ${ }^{26}$ by an independent and experienced pediatric neuroradiologist (NR) who was blinded to the clinical outcomes: 0 , normal MRI; $1 a$, minimal cerebral lesions only with no involvement of BGT (basal ganglia and thalami), ALIC (anterior limb of the internal capsule), PLIC (posterior limb of the internal capsule) or WS (watershed) infarction; $1 b$, more extensive cerebral lesions only with no involvement of BGT, ALIC, PLIC or WS infarction; $2 a$, any BGT, ALIC, PLIC or WS infarction noted without any other cerebral lesions; $2 b$, involvement of either BGT, ALIC, PLIC or area of infarction and additional cerebral lesions; and 3, cerebral hemispheric devastation. All infants were assigned a pattern of injury score without knowledge of any clinical information.

Certified investigators performed a standardized neurological exam ${ }^{10}$ at $\leqslant 6 \mathrm{~h}$ of age, $24 \pm 6 \mathrm{~h}$ of age and as close as possible to NICU discharge. For the certification process each site PI (principal investigator) was considered the gold standard examiner after orientation and review of the examination with two senior investigators ( $\mathrm{SS}$ and $\mathrm{AL}$ ). Additional physician examiners reviewed the definitions of the examination components from the study manual of procedures and then performed independent neurologic examinations within $1 \mathrm{~h}$ of the examination performed by the $\mathrm{PI}$ on three term infants, including two infants with abnormal findings. The investigator was certified if all three examinations achieved concordance with that of site PI regarding stage of encephalopathy. At discharge, the following additional features were recorded: gag reflex, clonus, fisted hand, abnormal movement and persistent asymmetric tonic neck reflex. Abnormal neurological exam at discharge was defined as any abnormal category of the modified Sarnat or the presence of any of the additional features. Maternal, perinatal and neonatal variables were recorded and entered in Research Electronic Data Capture (RedCap). Clinical data were centralized at McGill University Health Center.

\section{Secondary outcomes}

Pre-defined secondary outcomes were the percentage of infants with each of the primary outcome measures (abnormal aEEG or seizures $<9 \mathrm{~h}, \mathrm{MRI}$ or neurological exam), progression or persistence of abnormal neurological exam during hospitalization, occurrence of seizures at any time, length of hospital stay, need for gavage feeds or gastrostomy tube at discharge to home or in-hospital mortality. Follow-up of survivors at 18-24 months of age is ongoing.

Statistical analysis and sample size

Data were described as mean \pm standard deviation, number (\%) or median (interquartile range) where appropriate. A total sample size of 50 infants was calculated based on an expected rate of brain injury of $20 \%{ }^{6}$ and using a $\mathrm{Cl}$ of $95 \%$ to obtain a precision of $10 \%$ (range 10-30\%). A larger number of patients were enrolled in anticipation of the inability to acquire all three components of the primary outcome and loss to follow-up prior to 18 month visit. Analyses were performed with NCSS 11 Statistical Software (PASS 14: Power analysis and sample size software) and a $P$-value of $<0.05$ was considered statistically significant.

\section{RESULTS}

During the study period a total of 356 infants were admitted to the NICU for neurological evaluation for possible treatment with therapeutic hypothermia; 311 (87\%) were screened by the certified examiners. Of these, 76 (24\%) were classified as having mild NE and 63 (83\%) were enrolled (Figure 1). Each center enrollment is provided as supplementary material (Appendix 1). Fifty-four (86\%) infants had data on components of the primary outcome. There were no differences in baseline characteristics between the nine infants without data on all primary outcome measures and infants included in this report (data not shown). Maternal and perinatal characteristics and neonatal demographics are described in Tables 1 and 2.

The primary outcome of any abnormality on early aEEG, brain $\mathrm{MRI}<30$ days of age, or neurological exam at discharge occurred in $28 / 54$ (52\%) infants (Table 3). Only one infant (2\%) had the composite of all three abnormal primary outcomes and no infant had seizures at $<9 \mathrm{~h}$ of age. The combinations of the primary outcomes components are presented on Table 4.

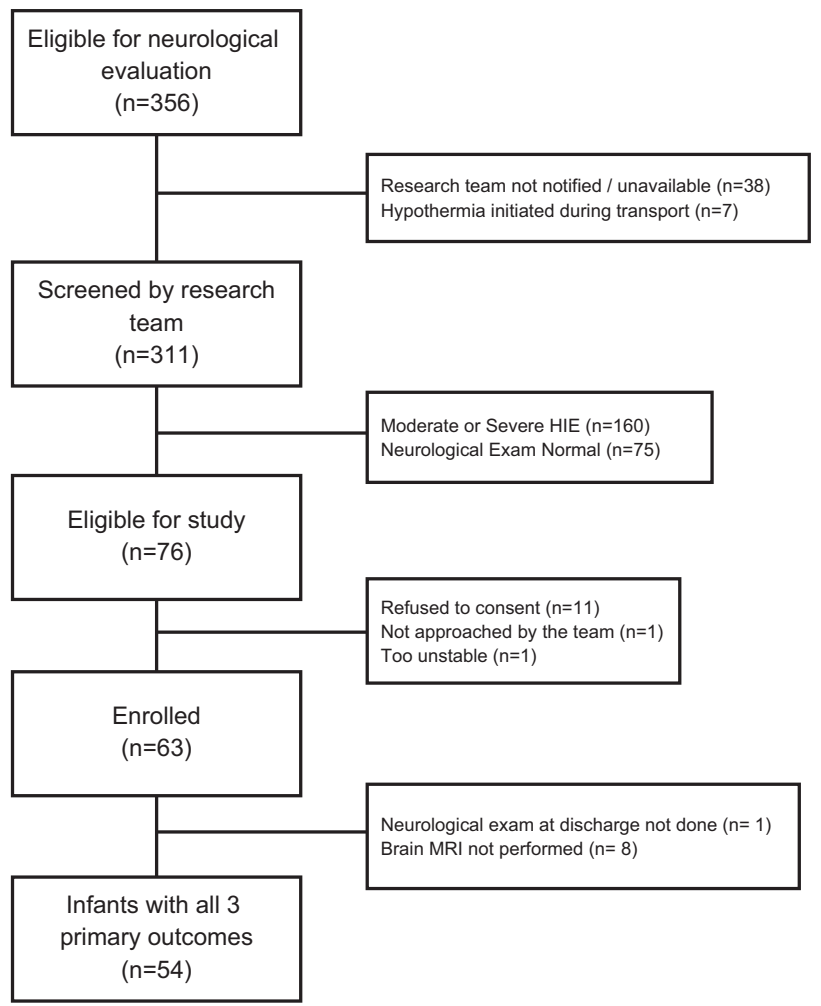

Figure 1. Flowchart of patient enrollment. 
Table 1. Maternal and perinatal characteristics

\begin{tabular}{lc}
\hline Characteristics & Results ( $\mathrm{n}=54$ ) \\
\hline Maternal & \\
Age (years) & $31 \pm 6$ \\
Primigravida & $27(50)$ \\
Ethnicity: white & $18(33)$ \\
Education: college & $29 / 53(55)$ \\
Gestational hypertension & $2(4)$ \\
Preeclampsia & $2(4)$ \\
Diabetes mellitus & $3(6)$ \\
Gestational diabetes mellitus & $6(11)$ \\
& \\
Perinatal & \\
Fever & $5(9)$ \\
GBS positive & $11(20)$ \\
GBS unknown & $17(31)$ \\
Prolonged rupture of membrane (>18 h) & $10(19)$ \\
Chorioamnionitis & $7(13)$ \\
Maternal antibiotics & \\
Antepartum hemorrhage & $20(37)$ \\
Abnormal fetal heart rate pattern & $6(11)$ \\
Meconium stained amniotic fluid & $41(76)$ \\
Cord accidents & $27(50)$ \\
Nuchal cord & $2(4)$ \\
Maternal hemodynamic instability & $11(20)$ \\
Shoulder dystocia & $1(2)$ \\
Cesarean section (all) & $2(4)$ \\
Cesarean section+abnormal CTG & $26(48)$ \\
Vaginal delivery with forceps or vacuum & $23(88)$ \\
Vaginal delivery without forceps or vacuum & $11(20)$ \\
\hline Abbreviations: CTG, cardiotocography; GBS, group & $17(32)$ \\
aChorioamnionitis (clinical = 4; histological =2; or both = 1 ). & b Indications \\
of antibiotics administration were: GBS prophylaxis (10), chorioamnionitis \\
(4), urinary tract infection (2) and PROM (4). Results are expressed as \\
mean \pm s.d., n/N (\%) or $n$ (\%). \\
\end{tabular}

Table 2. Neonatal demographics

\begin{tabular}{lc}
\hline Characteristics & Results ( $\mathrm{n}=54)$ \\
\hline Gestational age (week) & $39.4 \pm 1.4$ \\
Birth weight (gram) & $3.262 \pm 597$ \\
SGA (BW < 10th percentile) & $10(19)$ \\
Male & $34(63)$ \\
Outborn & $32(59)$ \\
Neonatal resuscitation ( $\leqslant 10$ min of life) & \\
Positive pressure ventilation & $48(89)$ \\
Intubation & $24(44)$ \\
Chest compression & $8(15)$ \\
Epinephrine administration & $1(2)$ \\
Assisted ventilation at 10 min & $36(67)$ \\
& \\
Apgar score & $2[1,3]$ \\
1 min & $5[3,6]$ \\
5 min & $7[5,8]$ \\
10 min & \\
Cord or postnatal blood gas (first hour of life) & $6.99 \pm 0.14(50)$ \\
pH & $75.4 \pm 24.8(46)$ \\
pCO2 & $18.3 \pm 4.9(43)$ \\
Bicarbonate & $14.6 \pm 4.9(49)$ \\
Base deficit & \\
\hline Abbreviations: BW, birth weight; SGA, mall for gestational age. Results are \\
presented as $n$ (\%), mean \pm s.d. (n) or median [IQR].
\end{tabular}

Table 3. Primary and secondary outcomes

\begin{tabular}{lc}
\hline Outcomes & Results $(\mathrm{n}=54)$ \\
\hline Primary outcome & \\
$\quad$ Any of abnormal aEEG, MRI or neurologic exam & $28(52)$ \\
Components of the primary outcome & \\
Abnormal aEEG & $4(7)$ \\
Abnormal brain MRI & $9(17)$ \\
Abnormal neurological exam & $22(41)$ \\
Abnormal aEEG and MRI & $1(2)$ \\
Abnormal aEEG and neurologic exam & $2(4)$ \\
Abnormal MRI and neurologic exam & $5(9)$ \\
Abnormal aEEG, MRI and neurologic exam & $1(2)$ \\
\hline Abbreviations: aEEG, amplitude integrated electroencephalography; MRI, \\
magnetic resonance image. Results are presented as $n(\%)$. No infant died \\
or was discharged home on gavage feeds.
\end{tabular}

Amplitude integrated EEG and Brain MRI

aEEG recordings were performed at a median age of $5.5 \mathrm{~h}$ (interquartile range; IQR $=4.8,6.4$ ). Fifty infants had a normal continuous aEEG and four (7\%) had a DNV tracing. Of these four, one infant also had an abnormal discharge exam and another one had all three components abnormal. There was a $100 \%$ concordance by the two readers in assignment of background activity and no seizures were detected. MRI was performed at a median age of 13 days (IQR $=7,23)$ and an abnormal pattern of injury was noted in $9(17 \%)$ infants: $1 a=3,1 b=4$ and $2 b=2$. Examples of brain MRI classification are provided on supplementary material (Appendix 2).

Neurological exam at discharge

A total of $22(41 \%)$ infants had abnormalities on the modified Sarnat score and/or extended neurological exam at discharge. Of these, 11 infants had mild NE on the Sarnat score, 7 had normal Sarnat score but abnormalities in the extended neurological exam, and 4 had both. The abnormalities on the extended neurological exam in the seven infants where the Sarnat score was normal were: abnormal movements $(n=1)$, fisted hands $(n=1)$ and persistent asymmetric tonic neck reflex $(n=5)$. The abnormalities noted on the extended exam of the four infants with both were: asymmetrical tonic neck reflex $(n=1)$, clonus $(n=1)$ and absent gag $(n=2)$. Details of the neurological exam at admission, $24 \mathrm{~h}$ of age and discharge are provided in Table 5.

\section{Secondary outcomes}

The percentage of infants with abnormalities on the modified Sarnat score and its categories decreased over time (Figure 2 and Table 5). Only one infant progressed to moderate NE at $36 \mathrm{~h}$ of age as evidenced by clinical seizures. This infant aEEG was normal but an abnormal neurological exam at discharge and evidence of brain injury on MRI (pattern 2b) was noted. The median length of hospital stay was 5 days (IQR $=3,9)$ with 40 infants $(74 \%)$ staying $>3$ days. There were no deaths and no infant was discharged home with gavage feeds or gastrostomy tube. Follow-up of survivors at 18-24 months of age is ongoing.

\section{DISCUSSION}

This is the first prospective and systematic evaluation of the outcomes of newborns diagnosed with mild NE secondary to hypoxia-ischemia at $<6 \mathrm{~h}$ of age, in the era of therapeutic hypothermia. Of the evaluated infants, $52 \%$ had abnormalities of either the early aEEG, brain MRI, or neurological exam at NICU discharge. Of these three outcome variables, abnormalities of the 
neurological examination at discharge were the most common. Specifically, these consisted of slightly increased peripheral tone, incomplete Moro reflex and abnormalities on the extended neurological exam. Although some trials of therapeutic hypothermia deviated from their inclusion criteria and enrolled infants with mild NE determined at $<6 \mathrm{~h}$ of age, ${ }^{12,14}$ there are no current recommendations to provide this therapy for mild NE given the absence of prospective outcome information for this specific

Table 4. Combinations of primary outcomes

\begin{tabular}{lccc}
\hline Outcomes & $\begin{array}{c}\text { Abnormal DC } \\
\text { exam }(\mathrm{N}=22)\end{array}$ & $\begin{array}{c}\text { Abnormal } \\
\text { aEEG }(\mathrm{N}=4)\end{array}$ & $\begin{array}{c}\text { Abnormal } \\
M R I(\mathrm{~N}=9)\end{array}$ \\
\hline $\begin{array}{l}\text { Abnormal DC } \\
\text { exam }(\mathrm{N}=22)\end{array}$ & 16 & 1 & 4 \\
$\begin{array}{l}\text { Abnormal aEEG } \\
(N=4)\end{array}$ & 1 & 2 & - \\
$\begin{array}{l}\text { Abnormal MRI } \\
(N=9)\end{array}$ & 4 & - & 4 \\
\hline
\end{tabular}

Abbreviations: aEEG, amplitude integrated electroencephalography; DC, discharge neurological exam; MRl, magnetic resonance image. Note: one infant had all three abnormal. group. $^{30}$ As cooling of mild NE infants has increased in clinical practice as evidenced by data registries of therapeutic hypothermia, ${ }^{18-20,32}$ the findings of this study are both important and timely. The measures used in this prospective cohort are readily available and have been used to predict outcome of infants with moderate and severe encephalopathy. ${ }^{20-29}$

\section{Early aEEG}

Abnormal aEEG was used as inclusion criteria in selected trials of hypothermia for infants with moderate or severe $\mathrm{NE}^{9,11,13}$ because of its ability to predict short and long-term outcomes. ${ }^{33-35}$ More recent studies have shown decreased predictive ability of early aEEG in infants treated with hypothermia; ${ }^{36,37}$ no information, however, is available for infants with mild NE. In this PRIME study, an abnormal aEEG occurred in only $7 \%$ of the cohort and were limited to a DNV background pattern. Of the latter, only one infant had an abnormal MRI (pattern 1b), and three infants had mildly abnormal neurological exam at discharge (tone, posture and Moro $=1$ ). These infants were not cooled as all centers followed the NICHD criteria to initiate hypothermia. Recently, 49 term infants treated with whole-body $\mathrm{TH}$ had aEEG monitoring initiated within $12 \mathrm{~h}$ of birth. Excessive discontinuity was independently predictive of abnormal developmental outcomes. ${ }^{38}$ However, in

Table 5. Details of the standardized modified Sarnat score

\begin{tabular}{|c|c|c|c|}
\hline \multicolumn{4}{|l|}{ Level of consciousness } \\
\hline $\begin{array}{l}\text { 1. Hyper-alert, jitteriness, high-pitched cry, exaggerated responds to minimal stimuli, } \\
\text { inconsolable }\end{array}$ & $14(26)$ & $12(22)$ & $3(6)$ \\
\hline 皮 & $1(2)$ & 0 & 0 \\
\hline 3. Stupor/coma & 0 & 0 & 0 \\
\hline \multicolumn{4}{|l|}{ Spontaneous activity } \\
\hline Normal & $35(65)$ & $46(85)$ & $51(94)$ \\
\hline 1. Normal or decreased & $16(30)$ & $8(15)$ & $3(6)$ \\
\hline 2. Decreased activity & $3(5)$ & 0 & 0 \\
\hline 3. No activity & 0 & 0 & 0 \\
\hline \multicolumn{4}{|l|}{ Posture } \\
\hline Normal & $30(56)$ & $42(78)$ & $51(94)$ \\
\hline \multicolumn{4}{|l|}{ Tone } \\
\hline Normal & $11(20)$ & $26(48)$ & $44(81.5)$ \\
\hline 1. Normal or slightly increased peripheral tone & $17(32)$ & $18(33)$ & $6(11.5)$ \\
\hline 2. $a=$ hypotonia (focal or general) or $b=$ hypertonia & $26(48)$ & $10(19)$ & $4(7)$ \\
\hline 3.- $a=$ flaccid or $b=$ rigid & 0 & 0 & 0 \\
\hline \multicolumn{4}{|l|}{ Reflex } \\
\hline Normal & $11(20)$ & $30(55.5)$ & $46(85)$ \\
\hline 1. Suck $=$ weak, poor $/$ Moro $=$ partial response, low threshold to illicit & $25(46)$ & $15(28)$ & 7 (13) \\
\hline 2. Suck $=$ weak or has bite $/$ Moro $=$ incomplete & $18(34)$ & $9(16.5)$ & $1(2)$ \\
\hline 3. Suck and Moro = absent & 0 & 0 & 0 \\
\hline \multicolumn{4}{|l|}{ Autonomic nervous system (pupils; heart rate; respirations) } \\
\hline Normal & $33(61)$ & $44(81.5)$ & $53(98)$ \\
\hline
\end{tabular}




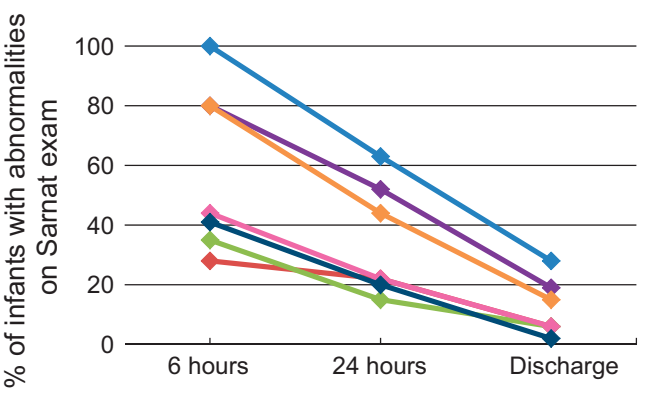

$$
\begin{array}{ll}
\prec \text { Modified Sarnat score } & \sim \text { Level of consciousness } \\
\prec \text { Spontaneous activity } & \sim \text { Posture } \\
\prec \text { Tone } & \sim \text { Primitive reflex }
\end{array}
$$

Figure 2. Abnormalities in the modified Sarnat exam and its components over time. The percentage of infants with any abnormality on the modified Sarnat score (mild NE) decreased over time to $28 \%$ (15 patients) at discharge. Please, note that in this cohort, seven patients had neurological abnormalities only on the extended exam at discharge and therefore are not included in this figure.

contrast to the PRIME study (aEEG performed at median age of $5.5 \mathrm{~h}$ ), aEEGs were acquired at 24 and $48 \mathrm{~h}$ of age in infants with moderate or severe NE receiving hypothermia and 'excessive discontinuity' was analyzed using special EEG software. Thus, the significance of a DNV background in the mild NE population included in this study is unknown.

\section{Brain MRI}

Data from randomized trials ${ }^{25-27}$ and retrospective cohorts ${ }^{39,40}$ have established a high PPV of specific brain MRI abnormalities in infants with moderate or severe NE treated with hypothermia. For infants with no or less-severe brain injury on MRI, there is less certainty of the long-term prognosis. ${ }^{40}$ In the present study we used the NICHD-NRN MRI scoring system, which was validated, in the largest number of infants from a therapeutic hypothermia trial. This scoring system indicated associations between patterns of brain injury and death or disability at 18 months ${ }^{39}$ and 6 to 7 years of age. ${ }^{26}$ In our study, 7/9 patients with an abnormal MRI had patterns scored as $1 \mathrm{a}$ or $1 \mathrm{~b}$. The previously reported frequency of death or moderate to severe disability associated with those scores among infants with moderate or severe NE varied from $17 \%$ (1a) to $25 \%(1 b) .{ }^{26}$ The association of MRI abnormalities in patients with mild NE with childhood outcomes has not been determined. However, two infants in our cohort had a more concerning pattern of injury, with involvement of the basal ganglia and thalamus ( $2 \mathrm{~b})$, a pattern that has been associated with a $65 \%$ frequency of death or moderate to severe disability in infants with moderate or severe NE treated with hypothermia. ${ }^{26}$

\section{Standardized neurological exam at discharge}

A low frequency of abnormalities on the discharge exam was reported among infants enrolled in the NRN whole-body cooling trial. ${ }^{28}$ However, the persistence of abnormalities even among infants with no or mild NE at discharge was associated with an increased risk of disability at 18 months of age. ${ }^{28}$ Furthermore, the presence of additional findings of the extended exam such as gag reflex, clonus, fisted hand, abnormal movement and persistent asymmetric tonic neck reflex has also been associated with increased odds of death/disability. ${ }^{28}$ In the present study 11 (20\%) infants had abnormalities in the extended exam at discharge. The association between these abnormalities and 18-24 months outcomes in mild NE is unknown.

The results of the prospective PRIME cohort differ from a prior retrospective cohort study where the outcomes of infants with mild NE at $<6 \mathrm{~h}$ of life and not treated with hypothermia were reported. ${ }^{6}$ In that study, $12(20 \%)$ of 60 infants classified as mild $\mathrm{NE}$ experienced an abnormal short-term outcome including feeding difficulties, abnormal brain MRI, seizures and abnormal neurologic exam at discharge or death. However, serial neurologic examinations were not done, the discharge neurologic examination was not standardized and brain MRI was performed in only $11 \%$ of infants precluding a precise estimate of the incidence of abnormal short-term outcomes. In two trials of therapeutic hypothermia ${ }^{12,14} \sim 20 \%$ of infants with mild NE were enrolled although not intended based on the inclusion criteria. Post hoc analysis of each trial indicated different outcomes among these infants. In the ICE trial, $25 \%$ of cooled and $33 \%$ of control infants with mild NE developed death or disability at 18 months without a treatment difference. ${ }^{14}$ In contrast, there was no reported death or disability among mild NE infants in the trial by Zhou et al. ${ }^{12}$

The PRIME study has several strengths, including a prospective design with serial neurological examinations, enrollment at multiple centers from four different countries, certification of all personnel responsible for the neurological exam, pre-defined outcome variables, and central readers' interpretation of aEEG and brain MRI. Although only 63 infants were enrolled, the sample size was pre-planned to be sufficient for the primary outcome. An important issue is the definition of mild NE since all prior studies have not provided a clear definition. In the PRIME cohort, all infants had evidence of significant perinatal acidosis and/or a hypoxic-ischemic event with need for resuscitation, along with neurological abnormalities insufficient to meet cooling criteria. We recognize that the definition used may be considered arbitrary and quite broad since mild NE infants could have different number of abnormalities from a total of six categories and that these could include one or two moderate or severe abnormalities. However, the definition used was consistently and prospectively applied across all centers. Limitations of PRIME are the long period required for enrollment, absence of follow-up aEEG at different time points or continuously, absence of all outcome measures on some infants, and the relative center imbalance in patient enrollment (Supplementary material - Appendix). During study design there were limited data on short-term outcomes of mild NE infants ${ }^{6,7}$ and systematic data on long-term outcomes (from the pre-hypothermia era) was favorable. ${ }^{4,5}$ Thus, a low frequency of short-term abnormalities was expected and our primary objective was to determine whether mild NE diagnosed at $<6 \mathrm{~h}$ of age was associated with short-term neurological abnormalities. Follow-up assessment at 18-24 months was added subsequently, before study initiation, as a secondary outcome.

\section{CONCLUSION}

In this prospective multicenter study of infants with mild NE, a large proportion manifested abnormal short-term outcomes. The functional impact of these findings on neurodevelopment is unclear but some of the abnormalities found on neurological exam at discharge and patterns of injury on brain MRI have been associated with childhood disability among infants with moderate or severe NE. Thus, future research should consider safety and efficacy assessment of neuroprotection for mild NE.

\section{CONFLICT OF INTEREST}

The authors declare no conflict of interest.

\section{ACKNOWLEDGEMENTS}

Funding source: Chatchay Prempunpong was funded by a scholarship for her Neonatal Perinatal Medicine fellowship training from the Department of Pediatrics at McGill University. Dr L Chalak is supported by NIH Grant K23HD069521. Paolo Montaldo and Sudhin Thayyil are supported by grants from the National Institute of 
Health Research (UK) and Biomedical Research Centre, Imperial College London. Clinical Trial registry name and registration number: ClinicalTrials.gov.-NCT01747863.

\section{REFERENCES}

1 Black RE, Cousens S, Johnson HL, Lawn JE, Rudan I, Bassani DG et al. Global, regional, and national causes of child mortality in 2008: a systematic analysis. Lancet 2010; 375(9730): 1969-1987.

2 Sarnat HB, Sarnat MS. Neonatal encephalopathy following fetal distress: a clinical and electroencephalographic study. Arch Neurol 1976; 33(10): 696-705.

3 Levene MI, Grindulis H, Sands C, Moore JR. Comparison of two methods of predicting outcome in perinatal asphyxia. Lancet 1986; 327(8472): 67-69.

4 Finer NN, Robertson CM, Richards RT, Pinnell LE, Peters KL. Hypoxic-ischemic encephalopathy in term neonates: perinatal factors and outcome. J Pediatr 1981; 98(1): 112-117.

5 Robertson C, Finer N. Term infants with hypoxic-ischemic encephalopathy: outcome at 3.5 years. Dev Med Child Neurol 1985; 27(4): 473-484.

6 DuPont TL, Chalak LF, Morriss MC, Burchfield PJ, Christie L, Sánchez PJ. Short-term outcomes of newborns with perinatal acidemia who are not eligible for systemic hypothermia therapy. J Pediatr 2013; 162(1): 35-41.

7 Gagne-Loranger M, Sheppard M, Ali N, Saint-Martin C, Wintermark P. Newborns Referred for Therapeutic Hypothermia: Association between initial degree of encephalopathy and severity of brain Injury (what about the newborns with mild encephalopathy on admission?). Am J Perinatol 2016; 33(2): 195-202.

8 Murray DM, O'Connor CM, Ryan CA, Korotchikova I, Boylan GB. Early EEG grade and outcome at 5 Years after mild neonatal hypoxic ischemic encephalopathy. Pediatrics 2016; 138(4): e20160659.

9 Gluckman PD, Wyatt JS, Azzopardi D, Ballard R, Edwards AD, Ferriero DM et al. Selective head cooling with mild systemic hypothermia after neonatal encephalopathy: multicentre randomised trial. Lancet 2005; 365(9460): 663-670.

10 Shankaran S, Laptook AR, Ehrenkranz RA, Tyson JE, McDonald SA, Donovan EF et al. Whole-body hypothermia for neonates with hypoxic-ischemic encephalopathy. N Engl J Med 2005; 353(15): 1574-1584.

11 Azzopardi DV, Strohm B, Edwards AD, Dyet L, Halliday HL, Juszczak E et al. Moderate hypothermia to treat perinatal asphyxial encephalopathy. $N$ Engl J Med 2009; 361(14): 1349-1358.

12 Zhou WH, Cheng GQ, Shao XM, Liu XZ, Shan RB, Zhuang DY et al. Selective head cooling with mild systemic hypothermia after neonatal hypoxic-ischemic encephalopathy: a multicenter randomized controlled trial in china. J Pediatr 2010; 157 (3): 367-372.

13 Simbruner G, Mittal RA, Rohlmann F, Muche R. neo.nEURO.network Trial Participants. Systemic hypothermia after neonatal encephalopathy: outcomes of neo. nEURO.network RCT. Pediatrics 2010; 126(4): e771-e778.

14 Jacobs SE, Morley CJ, Inder TE, Stewart MJ, Smith KR, McNamara PJ et al. WholeBody hypothermia for term and near-term newborns with hypoxic-ischemic encephalopathy: a randomized controlled trial. Arch Pediatr Adolesc Med 2011; 165(8): 692-700.

15 Shankaran S, Pappas A, McDonald SA, Vohr BR, Hintz SR, Yolton K et al. Childhood outcomes after hypothermia for neonatal encephalopathy. N Engl J Med 2012; 366(22): 2085-2092.

16 Azzopardi D, Strohm B, Marlow N, Brocklehurst P, Deierl A, Eddama O et al. Effects of hypothermia for perinatal asphyxia on childhood outcomes. N Engl J Med 2014; 371(2): 140-149.

17 Soll R. Cooling for newborns with hypoxic ischemic encephalopathy. Neonatology 2013; 104(4): 260-262.

18 Kracer B, Hintz SR, Van Meurs KP, Lee HC. Hypothermia therapy for neonatal hypoxic ischemic encephalopathy in the state of California. J Pediatr 2014; 165(2): 267-273.

19 Massaro AN, Murthy K, Zaniletti I, Cook N, DiGeronimo R, Dizon M et al. Short-term outcomes after perinatal hypoxic ischemic encephalopathy: a report from the Children's Hospitals Neonatal Consortium HIE focus group. J Perinatol 2015; 35(4): 290-296.

20 Shankaran S, Pappas A, McDonald SA, Laptook AR, Bara R, Ehrenkranz RA et al. Predictive value of an early amplitude integrated electroencephalogram and neurologic examination. Pediatrics 2011; 128(1): e112-e120.
21 Murray DM, Boylan GB, Ryan CA, Connolly S. Early EEG findings in hypoxicischemic encephalopathy predict outcomes at 2 Years. Pediatrics 2009; 124(3): e459-e467.

22 Shany E, Goldstein E, Khvatskin S, Friger MD, Heiman N, Goldstein M et al. Predictive value of amplitude-integrated electroencephalography pattern and voltage in asphyxiated term infants. Pediatr Neurol 2006; 35(5): 335-342.

23 Kharoshankaya L, Stevenson NJ, Livingstone V, Murray DM, Murphy BP, Ahearne $\mathrm{CE}$ et al. Seizure burden and neurodevelopmental outcome in neonates with hypoxic-ischemic encephalopathy. Dev Med Child Neurol 2016; 58: 1242-1248.

24 Glass HC, Glidden D, Jeremy RJ, Barkovich AJ, Ferriero DM, Miller SP. Clinical Neonatal Seizures are Independently Associated with Outcome in Infants at Risk for Hypoxic-Ischemic Brain Injury. J Pediatr 2009; 155(3): 318-323.

25 Shankaran S, McDonald SA, Laptook AR, Hintz SR, Barnes PD, Das A et al. Neonatal magnetic resonance imaging pattern of brain injury as a biomarker of childhood outcomes following a trial of hypothermia for neonatal hypoxic-ischemic encephalopathy. J Pediatr 2015; 167(5): 987-993.

26 Rutherford M, Ramenghi LA, Edwards AD, Brocklehurst $P$, Halliday $H$, Levene $M$ et al. Assessment of brain tissue injury after moderate hypothermia in neonates with hypoxic-ischaemic encephalopathy: a nested substudy of a randomised controlled trial. Lancet Neurology 2010; 9(1): 39-45.

27 Cheong JL, Coleman L, Hunt RW, Lee KJ, Doyle LW, Inder TE et al. Infant Cooling Evaluation Collaboration. Prognostic utility of magnetic resonance imaging in neonatal hypoxic-ischemicencephalopathy. Arch Pediatr Adolesc Med 2012; 166 (7): 634-640.

28 Shankaran S, Laptook AR, Tyson JE, Ehrenkranz RA, Bann CM, Das A et al. Evolution of encephalopathy during whole body hypothermia for neonatal hypoxicischemic encephalopathy. J Pediatr 2012; 160(4): 567-572.

29 Murray DM, Bala P, O'Connor CM, Ryan CA, Connolly S, Boylan GB. The predictive value of early neurological examination in neonatal hypoxic-ischaemic encephalopathy and neurodevelopmental outcome at 24 months. Dev Med Child Neurol 2010; 52(2): e55-e59.

30 Hellstrom-Westas L, Rosen I. Continuous brain-function monitoring: state of the art in clinical practice. Semin Fetal Neonatal Med 2006; 11(6): 503-511.

31 Toet MC, Lemmers PM. Brain monitoring in neonates. Early Hum Dev 2009; 85(2): 77-84.

32 Akula VP, Joe P, Thusu K, Davis AS, Tamaresis JS, Kim S et al. A randomized clinical trial of therapeutic hypothermia mode during transport for neonatal encephalopathy. J Pediatr 2015; 166(4): 856-861.

33 Eken P, Toet MC, Groenendaal F, de Vries LS. Predictive value of early neuroimaging, pulsed Doppler and neurophysiology in full term infants with hypoxic-ischaemic encephalopathy. Arch Dis Child Fetal Neonatal Ed 1995; 73(2): F75-F80.

34 Hellstrom-Westas L, Rosen I, Svenningsen NW. Predictive value of early continuous amplitude integrated EEG recordings on outcome after severe birth asphyxia in full term infants. Arch Dis Child Fetal Neonatal Ed 1995; 72(1): F34-F38.

35 Toet MC, Hellstrom-Westas L, Groenendaal F, Eken P, de Vries LS. Amplitude integrated EEG 3 and 6 hours after birth in full term neonates with hypoxicischaemic encephalopathy. Arch Dis Child Fetal Neonatal Ed 1999; 81(1): F19-F23.

36 Azzopardi DTOBY study group. Predictive value of the amplitude integrated EEG in infants with hypoxic ischaemic encephalopathy: data from a randomised trial of therapeutic hypothermia. Arch Dis Child Fetal Neonatal Ed 2014; 99(1): F80-F82.

37 Thoresen M, Hellstrom-Westas L, Liu X, de Vries LS. Effect of hypothermia on amplitude-integrated electroencephalogram in infants with asphyxia. Pediatrics 2010; 126(1): e131-e139.

38 Dunne JM, Wertheim D, Clarke P, Kapellou O, Chisholm P, Boardman JP et al. Automated electroencephalographic discontinuity in cooled newborns predicts cerebral MRI and neurodevelopmental outcome. Arch Dis Child Fetal Neonatal Ed 2017; 102(1): F58-F64.

39 Bonifacio S, Glass HC, Vanderpluym J, Agrawal AT, Xu D, Barkovich AJ et al. Perinatal events and early magnetic resonance imaging in therapeutic hypothermia. J Pediatr 2011; 158(3): 360-365.

40 Rollins N, Booth T, Morriss MC, Sanchez P, Heyne R, Chalak L. Predictive value of neonatal MRI showing no or minor degrees of brain injury after hypothermia. Pediatr Neurol 2014; 50(5): 447-451.

Supplementary Information accompanies the paper on the Journal of Perinatology website (http://www.nature.com/jp) 